\title{
Biomedical application of greenly synthesized silver nanoparticles using the filtrate of Trichoderma viride: Anticancer and immunomodulatory potentials
}

\author{
Bukola Christianah Adebayo-Tay0 ${ }^{1, A, C-F}$, Gbemisola Elisabeth 0gunleye ${ }^{1, B-F}$, Omonike 0gbole ${ }^{2, C, F}$ \\ ${ }^{1}$ Department of Microbiology, University of Ibadan, Nigeria \\ ${ }^{2}$ Department of Pharmacognosy, University of Ibadan, Nigeria \\ A - research concept and design; $\mathrm{B}$ - collection and/or assembly of data; $\mathrm{C}$ - data analysis and interpretation; \\ $D$ - writing the article; $E$ - critical revision of the article; $F$ - final approval of the article
}

Address for correspondence

Bukola Christianah Adebayo-Tayo

E-mail: bukola.tayo@gmail.com

Funding sources

None declared

Conflict of interest

None declared

\section{Acknowledgements}

We appreciate the authorities of University of Ibadan in Nigeria for providing the platform and access to some facilities used for this study.

Received on August 26, 2019

Reviewed on November 3, 2019

Accepted on January 3, 2020

\begin{abstract}
Background. Green route biosynthesis of silver nanoparticles using Trichoderma viride (T. viride) filtrate (TVFSNPS) can serve as an alternative to antibiotics and as an effective drug delivery to combat cancer and act as an immune-stimulator.
\end{abstract}

Objectives. To biosynthesize silver nanoparticles (SNPS) with T. viride filtrate using green route and to characterize and determine the cytotoxic and immunomodulatory potential of nanoparticles.

Material and methods. Trichoderma viride filtrate was used for biosynthesizing SNPs. The biosynthesized SNPs were characterized using UV-visible spectroscopy, Fourier transform infrared spectroscopy (FTIR), scanning electron microscopy (SEM) and energy dispersive X-ray (EDX). The cytotoxic properties against Hep-2C and rotavirus and the immunomodulatory potential were evaluated.

Results. Trichoderma viride filtrate was able to bio-reduce $\mathrm{AgNO}_{3}$ to $\mathrm{SNPs}$. The surface plasmon resonance peak was at $450 \mathrm{~nm}$. The presence of aldehydes, amino acids, ethers, esters, carboxylic acids, hydroxyl groups, and phenol among others indicates the capping and stabilization of proteins in the nanoparticles. The nanoparticles were spherical with a size of $0.1-10.0 \mathrm{~nm}$. The EDX analysis revealed a strong signal of silver (Ag). The TVFSNPs had a cytotoxic effect on Hep2C and rotavirus in a dose-dependent manner and increased the production of immunoglobulin $(\lg ) A(\lg A)$ and $\lg M$.

Conclusions. Trichoderma viride filtrate contained some biochemicals that can bio-reduce silver nitrate $\left(\mathrm{AgNO}_{3}\right)$ for SNPs biosynthesis. The anticancer and immunostimulatory potential justifies the biomedical application and biotechnological relevance of $T$. viride.

Key words: cytotoxicity, immunomodulation, Trichoderma spp, filtrate, biosynthesized silver nanoparticles

Cite as

Adebayo-Tayo BC, Ogunleye GE, Ogbole 0. Biomedical application of greenly synthesized silver nanoparticles using the filtrate of Trichoderma viride: Anticancer and immunomodulatory potentials. Polim Med. 2019;49(2):57-63. doi:10.17219/pim/116086

DOI

10.17219/pim/116086

Copyright

○ 2020 by Wroclaw Medical University

This is an article distributed under the terms of the

Creative Commons Attribution 3.0 Unported (CC BY 3.0)

(https://creativecommons.org/licenses/by/3.0/) 


\section{Introduction}

Nanobiotechnology is a new research field of biotechnology and engineering which involves which involve investigating nanoparticles synthesis which involve investigating nanoparticles synthesis and regulating the connection at a cellular level between synthetic materials and biological systems. ${ }^{1,2}$ Biosynthesis of metal nanoparticles is of great interest in nanoscience. ${ }^{3}$ Noble metals such as gold, silver, platinum, and lead are used in the biosynthesis of nanoparticles, in which silver $(\mathrm{Ag})$ is crucial for nanoparticles biosynthesis in biomedicine.

Nanoparticles have various applications in opto-electronics, diagnostic biological probes and catalysis., ${ }^{3,4}$ Nanoparticles can be synthesized chemically, physically and biologically. It is difficult to prepare silver nanoparticles (SNPs) with well-defined size using chemical methods; besides, they are toxic to the environment due to the use of toxic chemicals reducing agents such as borohydride, citrate, or other organic compounds. Physical methods give a low yield of nanoparticles, while the biological methods are eco-friendly, cost-effective have low toxicity, biocompatibility and a better control over size and shape of SNPs. ${ }^{5,6}$

Fungi like Trichoderma viride (T. viride), Trichoderma reesei (T. reesei), Alternaria flavus (A. flavus), Aspergillus niger (A. niger), Fusarium oxysporum (F. oxysporum) and Penicillium spp. are excellent sources of extracellular enzymes which influence nanoparticles synthesis. ${ }^{2,4}$ Fungi have potential in the production of nanoparticles at a faster rate on a large scale. ${ }^{4}$ Trichoderma spp. that frequently colonize soils, decaying wood and vegetable matter. They are the dominant part of the soil microflora in different habitats, have diverse metabolic capabilities and aggressively competitive nature. ${ }^{7}$ Trichoderma spp. are highly resistant to to biochemicals, chemicals and toxins. Most are strong opportunistic invaders, fast growing, prolific producers of spores and powerful antibiotics. ${ }^{8}$ Trichoderma species contain strains of vast economic importance, owing to their production of antibiotics and industrial enzymes and they act as biological control agents against plant pathogens., ${ }^{910}$ Some have an antagonistic activity against phytopathogenic fungi by using substrate colonization, antibiosis and mycoparasitism as the main mechanisms. This antagonistic potential is the basis for effective application of different Trichoderma strains as an alternative to chemical control against a wide variety of fungal plant pathogens. ${ }^{11}$ They are prolific producers of extracellular proteins. For instance, different strains produce more than 100 different metabolites that have antibiotic activities. ${ }^{8}$ Based on an eco-friendly approach, low toxicity, biocompatibility and immunomodulation, the potential of greenly synthesized nanoparticles and their applications in various fields cannot be overemphasized. However, nanoparticles can also act as an immunomodulatory agents alone or in combination with established therapeutic immunomodulatory agents. The use of fungi for the biosynthesis of SNPs provides advantages over chemical and physical methods, as it is cost-effective and environmentally friendly, and fungi can be used on a large scale. This study involves the biosynthesis and characterization of SNPs from T. viride and investigates its cytotoxic properties and immunomodulatory activities.

\section{Material and methods}

\section{Culture collection}

Trichoderma viride, which were previously isolated from soil samples, were obtained from the culture collection of the Microbial Physiology and Biochemistry Laboratory, Department of Microbiology, University of Ibadan, Nigeria. The culture was kept in potato dextrose agar and the stock culture was stored at $4^{\circ} \mathrm{C}$ and sub-cultured from time to time.

Cancer cell lines (human rhabdomysarcoma (RD) and laryngeal carcinoma (Hep-2C)) were supplied from the Centre for Disease Control (CDC), Atlanta, Georgia and maintained in WHO Polio Laboratory, Department of Virology, University of Ibadan, Nigeria. Ethical approval for the study was obtained from the University of Ibadan Animal Care and Use Research Ethics Committe.

\section{Production of cell filtrates of Trichoderma viride}

The cell filtrate of $T$. viride was produced by inoculating pure culture of $T$. viride into a sterile malt extract broth (MEB) and incubated at $25^{\circ} \mathrm{C}$ for 5 days. The medium was filtered using Whatman filter paper No. 1, the crude filtrates were collected and used for further studies.

\section{Biosynthesis of SNPs using Trichoderma viride}

The biosynthesis of SNPs using T. viride was done using modified method of Devi et al. ${ }^{3}$ Fifty milliliters of the cell filtrate was mixed with $50 \mathrm{~mL}$ of $1 \mathrm{mM}$ aqueous solution of silver nitrate $\left(\mathrm{AgNO}_{3}\right)$ prepared freshly in deionized water. The whole mixture was incubated at $25^{\circ} \mathrm{C}$ in dark place for 2 days. A flask with no addition of $\mathrm{Ag}^{+}$was used as a control. Formation of a brown solution from a colorless solution indicates SNPs biosynthesis.

\section{Characterization of the biosynthesized SNPs}

Formation of SNPs was observed visually for color change in comparison to control. The bio-reduction was monitored using UV-visible spectrum Lambda $25 \mathrm{UV} / \mathrm{Vis}$ spectrophotometer. UV/V with the resolution of $0.5 \mathrm{~nm} .{ }^{12}$ Fourier transform infrared spectroscopy (FTIR) was used to characterize the functional groups of SNPs. The dried 
SNPs were analyzed using potassium bromide $(\mathrm{KBr})$ pellet (FTIR grade) method in a ratio of 1:100. The spectrum was recorded using JASCO Corporation 2967-5 (Ishikawacho, Hachioji-shi Tokyo, Japan) FT/IR-6300 in the range of $500-4000 \mathrm{~cm}^{-1}$ at a resolution of $4 \mathrm{~cm}^{-1}$. The scanning electron microscopy (SEM) analysis of the gold-coated dried SNPs was done using a coater (JEOL, Akishima-shi, Japan; Model No. JFC-1600) and the images of SNPs were obtained using a scanninng electron microscope (ZEISS EVO-MA v. 10; Carl Zeiss AG, Oberkochen, Germany). ${ }^{13}$ The energy dispersive X-ray (EDX) analysis of the SNPs was done at a voltage of $4 \mathrm{keV}$ and current of $350 \mu \mathrm{A} .{ }^{13}$

\section{MTT assay}

The cytotoxicity assay of the samples was determined using MTT (3-4, 5-dimethyl thiazole-2yl)-2, 5-diphenyl tetrazolium bromide) assay. The cell filtrate and the SNPs biosynthesized with $T$. viride filtrate (TVFSNPs) were redissolved in dimethyl sulfoxide (DMSO) to give a concentration of $10 \mathrm{mg} / \mathrm{mL}$, respectively. The stock $(0.1 \mathrm{~mL})$ was added to $0.9 \mathrm{~mL}$ of maintenance medium containing antibiotics to obtain a dilution of $1000 \mu \mathrm{g} / \mathrm{mL}$ (neat). Ten-fold serial dilutions of the samples were made from the "neat" using maintenance medium as diluent to obtain different concentrations. Fifty microliters of each diluent was dispensed into 96-well microtiter plates already seeded with monolayer of $\mathrm{RD}$ and Hep-2C in triplicates. The plates were incubated at $37^{\circ} \mathrm{C}$ in a carbon-dioxide environment and the cells were observed under microscope after $72 \mathrm{~h}$.

The MTT colorimetric assay was used to evaluate the reduction of viability of cell cultures in the presence and absence of metabolites. The ability of the SNPs to be cytotoxic was measured using the tetrazolium dye (MTT), which is metabolized by mitochondrial enzymes of viable (surviving) cells to an insoluble, colored formazan product. The level of metabolism that occurs in the individual well of the 96well microtiter plate is dependent on the number of healthy viable cells present. The plates were placed on a shaker for $15 \mathrm{~min}$, after which absorbance of insoluble formazan salts was assessed at $492 \mathrm{~nm}$ wavelength on a multi-well spectrophotometer (Titertek Uniskan, Thermo Scientific ${ }^{\mathrm{TM}}$ Multiskan $^{\mathrm{TM}}$ GO UV/Vis microplate spectrophotometer). ${ }^{14}$

\section{Immunommodulatory activity}

This study was conducted using female Swiss albino mice aged 6 weeks, weighing $20 \pm 4 \mathrm{~g}$. They were fed with rat pellets and given water ad libitum. The animals were allowed to acclimatize to the laboratory environment for 2 weeks and were later divided into groups for the experiment. Group 1 and 2 served as the control; Group 3 was administered with TVFSNPs and Group 4 was administered T. viride fungal filtrate (TVF). All the procedures used in this study conformed to the guidelines for care and use of animals in research and teaching.

\section{Determination of $\lg \mathrm{G}, \lg \mathrm{M}$ and $\lg \mathrm{A}$}

The immunoglobulin (Ig) G (IgG), IgA, IgM of the treated and untreated mice was determined by diluting the blood serum samples and the control samples in $0.9 \%$ saline (1:10). Twenty microliters of the diluted samples was added to $900 \mu \mathrm{L}$ of phosphate buffer and labeled sample A2. The absorbance of sample A1 was taken at $340 \mathrm{~nm}$. One hundred microliters of antibody reagents was added into the prepared samples and mixed properly. The reaction mixture was incubated for $5 \mathrm{~min}$. Absorbance of sample A2 and the control was taken at $340 \mathrm{~nm}$.

\section{Statistical analysis}

The analysis of variance (ANOVA) and SPSS v. 25 were used to statistically evaluate the data. Values are represented as the mean \pm standard deviation (SD) of the 3 replicates of each experiment.

\section{Results and discussion}

\section{Biosynthesis and characterization of SNPs}

The cell filtrate of $T$. viride was used for biosynthesis of SNPs. Figure 1 shows the visual detection of SNPs biosynthesized using filtrate from $T$. viride. Changes in color from yellow to dark brown were observed.

Nanoparticles possess more surface atoms than microparticles, which enhances their functional capabilities. Biocompatible synthesis of metal nanoparticles was encouraged to exploit the biological sources of nanoparticles, because it is cost-effective. ${ }^{10}$

The T. viride filtrate bio-reduced $\mathrm{AgNO}_{3}$ for SNPs biosynthesis. The bio-reduction potential of the filtrate from T. viride is in accordance with the work by Vahabi and Karimi, ${ }^{16}$ who reported that $T$. reesei is an eco-friendly fungus which biosynthesizes SNPs in a large-scale production, in which there was a change in color from yellow to dark brown.


Fig. 1. Visual detection of silver nanoparticles (SNPs) biosynthesized with Tricoderma viride filtrate (TVFSNPS)

A - silver nitrate $\left(\mathrm{AgNO}_{3}\right)$ solution; $\mathrm{B}-$ T. viride fungal filtrate (TVF);

C-TVFSNPS. 
The spectra obtained from the biosynthesized TVFSNPs are shown in Fig. 2. A broad-band spectrum between $350 \mathrm{~nm}$ and $550 \mathrm{~nm}$ was observed for TVFSNPs and the surface plasmon resonance (SPR) peak was at $450 \mathrm{~nm}$, indicating the formation of SNPs.

Strong SPR is very important in the synthesis of nanoparticles and it is characterized by UV-visible absorption spectroscopy. This result is similar to the study by Kanmani and Lim, ${ }^{17}$ in which SNPs showed a strong SPR peak at 400-550 $\mathrm{nm}$ with a broad band and size, indicating the formation of SNPs. ${ }^{17}$ Guangquan et $\mathrm{al}^{5}$ reported that UV-visible spectra of the cell filtrate with $\mathrm{AgNO}_{3}$ showed a strong broad peak at $440 \mathrm{~nm}$, indicating the presence of SNPs. ${ }^{5}$

The FTIR analysis of TVFSNPs is shown in Fig. 3. 13 bands were present at 3425.69, 2895.25, 2359.02, 1633.76, 1404.22, 1330.93, 1149.61, 1074.39, 968.3, 931.65, 891.14, 738.76 and $597.3 \mathrm{~cm}^{-1}$. The peaks at $3245.69 \mathrm{~cm}^{-1}$ and $2895.25 \mathrm{~cm}^{-1}$ were attributed to $\mathrm{O}-\mathrm{H}$ stretch of alcohol and $\mathrm{C}-\mathrm{H}$ symmetrical stretching of aldehydes. The absorption peaks at $2359.02 \mathrm{~cm}^{-1}$ and $1633.76 \mathrm{~cm}^{-1}$ were also attributed to the presence of $\mathrm{COOH}$ overtone and the presence of $\mathrm{C}=\mathrm{O}$ stretch of carboxylates. The absorption peaks at $1404.22 \mathrm{~cm}^{-1}$ and $1330.93 \mathrm{~cm}^{-1}$ corresponded to C-N stretch of primary amide and $\mathrm{C}-\mathrm{N}$ stretch of secondary amine. The peaks at $1449.61 \mathrm{~cm}^{-1}$ and $1074.39 \mathrm{~cm}^{-1}$ indicated the presence of $\mathrm{S}=\mathrm{O}$ sulfonic esters and $\mathrm{C}-\mathrm{N}$ stretch of aliphatic amines. The absorption peaks at $968.3 \mathrm{~cm}^{-1}, 931.65 \mathrm{~cm}^{-1}$ and $891.14 \mathrm{~cm}^{-1}$ corresponded to $\mathrm{C}=\mathrm{CH}_{2}$ alkenes out-ofplane bend, P-O-P stretch of pyrophosphate and C-O of epoxide. The absorption peaks at $738.76 \mathrm{~cm}^{-1}$ and $507.3 \mathrm{~cm}^{-1}$ indicated the presence of $\mathrm{C}-\mathrm{H}$ and disulfide. From the obser-

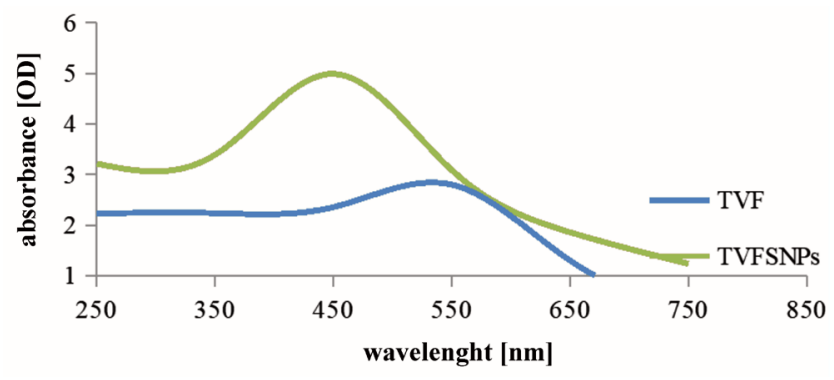

Fig. 2. UV-visible absorption spectra of TVFSNPs and TVF

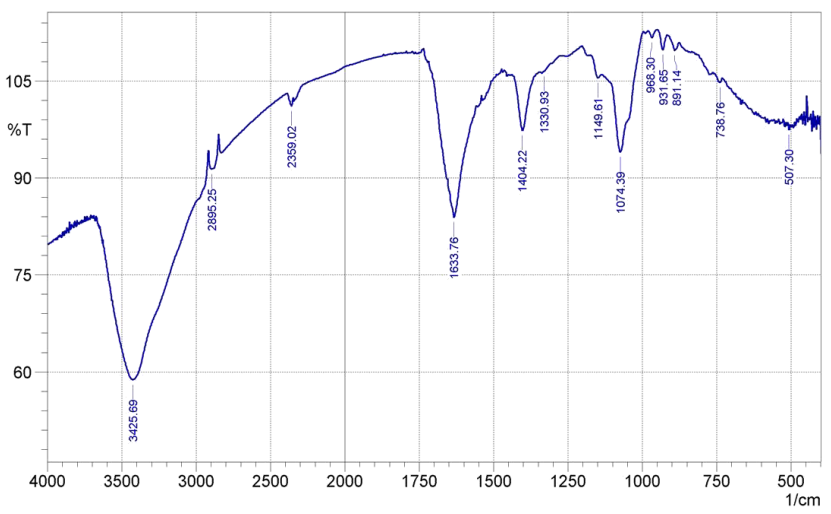

Fig. 3. Fourier transform infrared spectroscopy (FTIR) spectrum of TVFSNPs vation in the spectrum, the presence of alcohols, aldehydes, carboxylic acids, alkenes in the samples may be responsible for the reduction of $\mathrm{AgNO}_{3}$ to SNPs.

The FTIR spectra of TVFSNPs showed that different functional groups were present. Aldehydes, amino acids, ethers, esters, carboxylic acids, hydroxyl groups, phenol among others are responsible for the synthesis of SNPs. Carbonyl groups from the amino acid residues and peptides of proteins have a strong ability to bind to Ag. These proteins serve as a capping and stabilizing agent. Sonal et al. ${ }^{17}$ reported that the biomolecules, especially proteins from the filtrate of $F$. oxysporum, were responsible for synthesizing and stabilizing SNPs.

The TVFSNPs were further characterized by SEM, which showed the morphology and size of the biosynthesized SNPs. The SEM micrograph is shown in Fig. 4. The TVFSNPs were spherical and 0.01-10.0 nm in size.

A scanning electron microscope is an important tool for the characterization of SNPs. ${ }^{15-18}$ The shape of the TVFSNPs is in agreement with the study by Amal and Azzah, ${ }^{2}$ who reported that nanoparticles are spherical with a small percentage of elongated particles with a variation in particle size, $5 \mathrm{~nm}$ for $F$. oxysporum, $20 \mathrm{~nm}$ for A. niger and $25 \mathrm{~nm}$ Alternaria solani (A. solani).

The EDX analysis of biosynthesized TVFSNPs is shown in Fig. 5. Silver had the highest intensity in the range $0.0001-0.2574$.

The EDX analysis was used to determine the elemental composition of samples. Strong signals from Ag atoms in the nanoparticles were observed, while there were weaker signals from carbon, oxygen, sulfur, phosphorus, magnesium and sodium atoms. The presence of a strong Ag peak is a result of SPR. The carbon, oxygen, sulfur, phosphorus, magnesium and sodium signals may be due to the X-ray emission from proteins or enzymes present in the cell wall of the organisms. The presence of other EDX peaks for chlorine, sodium and oxygen was as a result of mixed precipitates present in the extract. Pnyabrata et al. had similar report. ${ }^{19-20}$
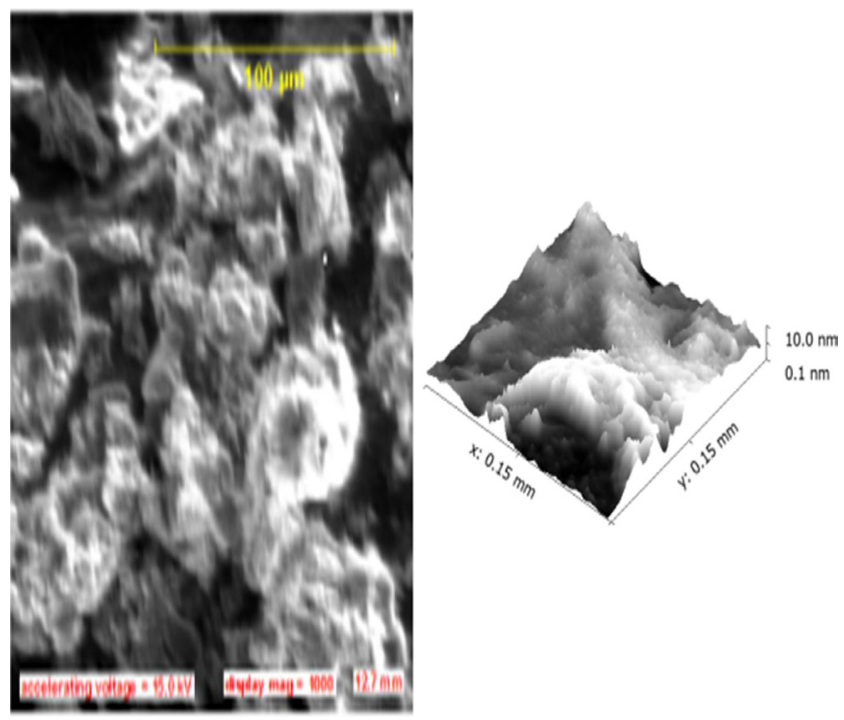

Fig. 4. A scanning electron micrograph of TVFSNPs 


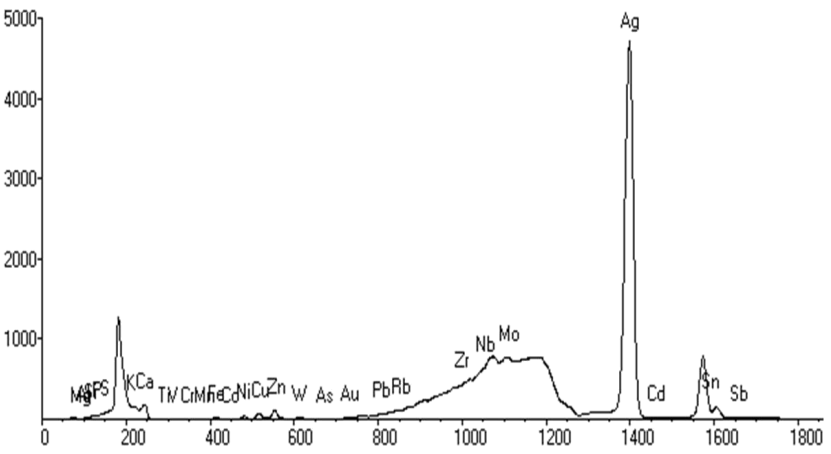

Fig. 5. Energy dispersive X-ray (EDX) analysis of TVFSNPs

\section{Cytotoxicity assay of the TVFSNPs against Hep-2C and rotavirus cell lines}

Cytotoxicity activity against hepatitis-2C (Hep-2C) and rotavirus cell lines was evaluated at different concentrations by MTT assay. Table 1 shows the $\mathrm{IC}_{50}(\mu \mathrm{g} / \mathrm{mL})$ and dose-dependent values for the in vitro cytotoxic activity against Hep-2C cell lines. It was observed that TVFSNPs inhibited the viability of Hep-2C cell lines in dose-dependent manner. Silver nanoparticles were not toxic at lower doses, while mild cytotoxicity was recorded at higher doses.

Table 2 shows the $\mathrm{IC}_{50}(\mu \mathrm{g} / \mathrm{mL})$ and dose-dependent values for the in vitro cytotoxic activity against rotavirus cell lines. The TVFSNPs did not exhibit significant cytotoxicity at their lower concentrations, while cytotoxicity increased at higher concentrations.

Cytotoxicity increased at higher TVFSNPs concentrations. The ability of the TVFSNPs to increase toxicity at a higher concentration may be due to metal nanoparticles overaccumulating inside the cell. It may also be due to the fact that SNPs interfere with the proper functioning of cellular proteins and induce subsequent changes in cellular chemistry. The cytotoxicity impact of SNPs in biological systems depends on their physiochemical properties. ${ }^{21}$
Vimbela et al. ${ }^{22}$ reported a dose-dependent cytotoxicity effect of nanoparticles against J774 and THPI cell lines, in which there were no cytotoxic effects at low doses $(10 \mu \mathrm{g})$, whereas mild cytotoxicity effects were observed at high doses of 100-150 $\mu \mathrm{g}$. Raman et al. reported the dose-dependent cytotoxicity potential of Melia azedarach SNPs against HeLa cells. ${ }^{24}$

The anti-proliferative effect of SNPs on cancer cell line has been reported. ${ }^{24,25}$ Choi et al. reported the cytotoxicity potential of SNPs on A2780 ovarian carcinoma cells and ovarian cancer stem cells at a high concentration. The cells are more sensitive to the treatment with SNPs. ${ }^{25}$

\section{Immunomodulatory activity of TVSNPs}

The immunomodulatory activity of the fungal filtrate and TVFSNPs is shown in Table 3. There was a significant difference in the immunomodulatory activity of the treatments using the biosynthesized TVFSNPs and the TVF on the treated mice.

Group 2, which included mice treated with sheep red blood cells, had the highest IgG. The IgA of the treated mice ranged from 75 to $258 \mathrm{mg} / \mathrm{dL}$. Group 3 (mice treated with TVFSNPs) had the highest IgG, while Group 4 (mice treated with TVF) had the lowest IgG. The IgM of the treated mice ranged from 96 to $24 \mathrm{mg} / \mathrm{dL}$. Group 3 had the highest IgM, while Group 4 had the lowest IgM.

The immunomodulatory potential of TVFSNPs based on in vivo immunological activity was investigated. The TVFSNPs showed significant immunostimulation of IgA and IgM. The ability of TVFSNPs to stimulate IgA and $\operatorname{IgM}$ in the immune system of the mice may be due to the easy engulfment of macrophages to the SNPs. Serum glycoproteins are stimulated to produce a subpopulation of white blood cells called lymphocyctes. This could be as a result of the nanoparticles stimulating macrophages activity which evolve from immune system to protect

Table 1. $I C_{50}(\mu \mathrm{g} / \mathrm{mL})$ and dose-dependent values for the in vitro cytotoxic activity against Hep-2C cell lines

\begin{tabular}{|c|c|c|c|c|c|c|c|}
\hline \multirow{2}{*}{ Samples } & \multicolumn{6}{|c|}{ Concentration $[\mu \mathrm{g} / \mathrm{mL}] \pm$ SEM } & \multirow{2}{*}{$\mathrm{IC}_{50}[\mu \mathrm{g} / \mathrm{mL}]$} \\
\hline & 0.01 & 0.1 & 1 & 10 & 100 & 1000 & \\
\hline $\mathrm{AgNO}_{3}$ & $0.627 \pm 0.02^{c}$ & $25.013 \pm 0.21^{\mathrm{a}}$ & $27.729 \pm 0.03^{b}$ & $34.036 \pm 0.02^{b}$ & $38.46 \pm 0.04^{d}$ & $55.793 \pm 0.03^{c}$ & $50.02 \pm 0.02^{b}$ \\
\hline TVFSNP & $0.623 \pm 0.01^{c}$ & $8.591 \pm 0.02^{c}$ & $20.348 \pm 0.06^{d}$ & $26.823 \pm 0.04^{d}$ & $47.89 \pm 0.21^{c}$ & $51.146 \pm 0.03^{d}$ & $54.27 \pm 0.02^{a}$ \\
\hline TVF & $1.316 \pm 0.03^{b}$ & $5.406 \pm 0.01^{d}$ & $22.187 \pm 0.06^{c}$ & $27.583 \pm 0.02^{c}$ & $49.756 \pm 0.09^{b}$ & $69.303 \pm 0.04^{\mathrm{a}}$ & $37.83 \pm 0.03^{d}$ \\
\hline CTX & $20.163 \pm 0.05^{a}$ & $22.75 \pm 0.03^{b}$ & $41.093 \pm 0.08^{a}$ & $54.556 \pm 0.09^{a}$ & $73.546 \pm 0.24^{a}$ & $67.946 \pm 0.02^{b}$ & $47.19 \pm 0.02^{c}$ \\
\hline
\end{tabular}

SEM - scanning electron microscopy; CTX - anticancer drug. Data presented as mean \pm standard deviation (SD).

Table 2. $I C_{50}(\mu \mathrm{g} / \mathrm{mL})$ and dose-dependent values for the in vitro cytotoxic activity of against rotavirus cell lines

\begin{tabular}{|l|c|c|c|c|c|c|c|}
\multirow{2}{*}{ Samples } & \multicolumn{5}{|c|}{ Concentration $[\mu \mathrm{g} / \mathrm{mL}] \pm$ SEM } & 100 & 1000 \\
\cline { 2 - 7 } & 0.01 & 0.1 & 1 & 10 & $I_{50}[\mu \mathrm{g} / \mathrm{mL}]$ \\
\hline $\mathrm{AgNO}_{3}$ & $2.083 \pm 0.02^{\mathrm{c}}$ & $17.951 \pm 0.02^{\mathrm{b}}$ & $22.386 \pm 0.02^{\mathrm{c}}$ & $24.113 \pm 0.02^{\mathrm{c}}$ & $25.163 \pm 0.03^{\mathrm{c}}$ & $96.606 \pm 0.02^{\mathrm{a}}$ & $31.00 \pm 0.06^{\mathrm{c}}$ \\
TVFSNP & $2.976 \pm 0.02^{\mathrm{b}}$ & $19.956 \pm 0.02^{\mathrm{a}}$ & $27.786 \pm 0.03^{\mathrm{b}}$ & $32.016 \pm 0.03^{\mathrm{b}}$ & $35.206 \pm 0.03^{\mathrm{b}}$ & $82.256 \pm 0.03^{\mathrm{d}}$ & $38.33 \pm 0.04^{\mathrm{b}}$ \\
TVF & $3.883 \pm 0.03^{\mathrm{a}}$ & $12.689 \pm 0.03^{\mathrm{c}}$ & $18.156 \pm 0.04^{\mathrm{d}}$ & $20.653 \pm 0.03^{\mathrm{d}}$ & $22.662 \pm 0.02^{\mathrm{d}}$ & $86.146 \pm 0.02^{\mathrm{b}}$ & $28.54 \pm 0.03^{\mathrm{d}}$ \\
CTX & $3.612 \pm 0.02^{\mathrm{a}}$ & $9.475 \pm 0.03^{\mathrm{d}}$ & $34.533 \pm 0.02^{\mathrm{a}}$ & $55.303 \pm 0.02^{\mathrm{a}}$ & $73.173 \pm 0.02^{\mathrm{a}}$ & $84.596 \pm 0.03^{\mathrm{c}}$ & $49.05 \pm 0.02^{\mathrm{a}}$ \\
\hline
\end{tabular}


Table 3. Immunomodulatory activity of TVFSNPS

\begin{tabular}{|c|c|c|c|c|c|c|c|}
\hline $\mathrm{S} / \mathrm{N}$ & Group & SRBC & SNPS & $\mathrm{FF}$ & $\operatorname{lgG}[\mathrm{mg} / \mathrm{dL}]$ & $\lg A[\mathrm{mg} / \mathrm{dL}]$ & $\lg M[\mathrm{mg} / \mathrm{dL}]$ \\
\hline 1 & GRP1a & - & - & - & 0.000 & 0.000 & 0.000 \\
\hline 2 & GRP1b & - & - & - & $79 \pm 0.65^{b}$ & $171 \pm 0.97^{c}$ & $38 \pm 0.12^{c}$ \\
\hline 3 & GRP2 & + & - & - & $118 \pm 0.23^{a}$ & $230 \pm 0.45^{b}$ & $73 \pm 0.26^{b}$ \\
\hline 4 & GRP3 & - & + & - & $48 \pm 0.27^{d}$ & $258 \pm 0.73^{a}$ & $96 \pm 0.22^{a}$ \\
\hline 5 & GRP4 & - & - & + & $63 \pm 0.39^{c}$ & $75 \pm 0.81^{d}$ & $24 \pm 0.17^{d}$ \\
\hline
\end{tabular}

$\mathrm{n}=6 ; \mathrm{p}<0.05$ - significant difference; GRP1a - mice not exposed to cigarette smoke and not treated; GRP1b - mice exposed to cigarette smoke and not treated; GRP2 - mice administered sheep red blood cells; GRP3 - mice administered TVFSNPs; GRP4 - mice administered TVF; SNPs - silver nanoparticles; FF - fungal filtrate; $\mathrm{SN}$ - serial number, SRBC - sheep red blood cell.

the host from potentially pathogenic agents, eliminate neoplastic cells and to reject non-self-components. Swarnakar et al. reported that the chemically synthesized nanoparticles act as an immunomodulatory agent alone or in combination with established therapeutic immunomodulatory agents, and can be a targeted drug/vaccine delivery vehicle to macrophages. ${ }^{27}$

\section{Conclusions}

The filtrate from $T$. viride mediated the biosynthesis of SNPs, which were spherical in shape and nontoxic at a lower concentration. The TVSNPs exhibited cytotoxicity against $\mathrm{Hep}-2 \mathrm{C}$ cell line and RD cell line in a dose-dependent manner and had immune-stimulation potential by increasing the production of IgA and IgM. The anticancer and immunomodulatory potential of TVSNPs justifies its biomedical application and showcases the biotechnological relevance of the fungus.

\section{ORCID iDs}

Bukola Christianah Adebayo-Tayo

(D) https://orcid.org/0000-0003-2404-1686

Gbemisola Elizabeth Ogunleye (1) https://orcid.org/0000-0003-2344-8177

Omonike Ogbole (i) https://orcid.org/0000-0002-6487-9494

\section{References}

1. Juhi S, Madan MS, Sarika G, Abhijeet S. Emerging role of fungi in nanoparticles synthesis and their applications. World J Pharm Sci. 2014;(3)9:1586-1613.

2. Amal AAJ, Azzah AG. Biosynthesis of silver nanoparticles by Aspergillus niger, Fusarium oxysporum and Alternaria solani. Afri J Biotechnol. 2015;(4):2170-2174.

3. Devi TP, Kulanthaivel S, Kamil D, Borah JL, Prabhakaran N. Biosynthesis of silver nanoparticles from Trichoderma species. India J Experimental Biol. 2013;(51)7:543-547.

4. Nikalje AP. Nanotechnology and its application in medicine. Medicinal Chem. 2015;5:81-89.

5. Guangquan L, Dan H, Yongang $Q$, et al. Fungus-mediated green synthesis of silver nanoparticles using Aspergillus terreus. Intern $J$ Molecular Sci. 2012;(13):466-467.

6. Sandhu SS, Shukla H, Shukla S. Biosynthesis of silver nanoparticles by endophytic fungi: Its mechanism, characterization techniques and antimicrobial potential. African J Biotechnol. 2017;(16)14:683-698.

7. Samuels GJ. Trichoderma: Systematics, the sexual state and ecology. Phytopathology. 2006;(96)2:195-206.

8. Harman GE, Howel CR, Viterbo A, Chet I, Lorito M. Trichoderma species - opportunistic, virulent plant symbionts. Nature Review Microbiol. 2004;(2):43-55.
9. Druzhinina IS, Komon-Zelazowska M, Ismaiel A, et al. Molecular phylogeny and species delimitation in the section Longibrachiatum of Trichoderma. Fungal Genetic Biol. 2012;(49)5:358-368.

10. Sivasithamparam K, Ghisalberti E. Secondary metabolism in Trichoderma and Gliocladium. In: Kubicek CP \& Harman GE (eds.), Trichoderma and Gliocladium. 1998;1:139-191. London, UK: Taylor \& Francis.

11. Babu K, Pallavi PN. Isolation, identification and mass multiplication of Trichoderma - an important bio-control agent. Inter J Pharmacy Life Sci. 2013;(4)1:2320-2323.

12. Ottoni CA, Simões MF, Fernandes $S$, et al. Screening of filamentous fungi for antimicrobial silver nanoparticles synthesis. AMB Express 2017;7:31-41.

13. Natarajan K, Selvaraj S, Murty VR. Microbial production of silver nanoparticles. DIG J Nanomater Bios. 2010;(5)1:135-140.

14. Nikhil SS, Mahesh B, Rahul B, et al. Biosynthesis of silver nanoparticles using extract from the producing fungal strain. Process Biochem. 2009;45:939-943.

15. Sukirtha R, Priyanka KM, Antony JJ, et al. Cytotoxic effect of green synthesized silver nanoparticles using Melia azedarach in vitro HeLa cell lines and lymphoma mice model. Process Biochem. 2010;11:1-34.

16. Vahabi Ali MG, Karimi, S. Biosynthesis of silver nanoparticles by fungus Trichoderma reesei used for large scale production of Ag nanoparticles. Intern J Nanosci. 2011;(1)1:65-79.

17. Kanmani P, Lim ST. Synthesis and structural characterization of silver nanoparticles using bacterial activity against food and multidrug resistant pathogens. Process Biochem. 2013;(48):1099-1106.

18. Sonal SB, Swapnil C, Aniket KG, Mahendra KR. Rapid synthesis of silver nanoparticles from Fusarium oxysporum by optimizing physicocultural conditions. ScientificWorldJournal. 2013;(10):1155-1167.

19. Nanda A, Raghavan CM. Antimicrobial efficacy of synthesized AgNPs from exopolysacharides (EPS) produced by Bacillus subtilis of medico-clinical sinks. Intern J Chemical Technol Res. 2014;(6)5:2914-2919.

20. Pnyabrata M, Absar A, Deendayal M, et al. Fungus-mediated synthesis of silver nanoparticles and their immobilization in the mycelia matrix: A novel biological approach to nanoparticle synthesis. Nano Lett. 2001;(1)10:515-519.

21. Usha MC, Gladys ARD. Biogenic synthesis of silver nanoparticles by Acacia nilotica and their antibacterial activity. Intern J Scientific Res. 2014;(3)6:27-29.

22. Vimbela GV, Ngo SM, Fraze C, Yang L, Stout DA. Antibacterial properties and toxicity from metallic nanomaterials. Inter J Nanomed. 2017;(12):3941-3965.

23. Faria F, Preeti B, Neelam P, Sarika S, Shivam P, Smita RV. Antimicrobial and immunomodulatory efficacy of extracellularly synthesized silver and gold nanoparticles by a novel phosphate solubilizing fungus Bipdaris tetramera. BMC Microbiology. 2015;(15):52.

24. Raman S, Muthukalingn K, Rajamanickam R, Sound AK, Palanivel K. Derived silver nanoparticles: A novel antitumor agent against Dalton's ascites lymphoma. Intern J Green Nanotechnol. 2012;(1)3:2-12.

25. Choi YJ, Lee HW, Lee YS, Shim da M, Seo SW. Differential cytotoxic potential of silver nanoparticles in human ovarian cancer cells and ovarian cancer stem cells. Int J Mol Sci. 2016;(17)12:2077.

26. Kovacs D, Szoke K, Igaz N, et al. Silver nanoparticles modulate ABC transporter activity and enhance chemotherapy in multidrug resistant cancer. Nanomedicine. 2016;12(3):601-610.

27. Swarnakar N, Thanki K, Jain S. Effect of co-administration of CoQ10loaded nanoparticles on the efficacy and cardio-toxicity of doxorubicin-loaded nanoparticles. RSC Adv. 2013;3:146-171. 